Check for updates

Cite this: Mater. Adv., 2022, 3,2447

Received 11th November 2021 Accepted 24th January 2022

DOI: $10.1039 / \mathrm{d} 1 \mathrm{ma} 01055 \mathrm{~g}$

rsc.li/materials-advances

\title{
Air-grown hybrid copper(I) halide single crystals: structural transformations and ultraviolet-pumped photoluminescence applications $\dagger$
}

\author{
Zhexin Song, ${ }^{a}$ Binyin Yu, ${ }^{a}$ Lingqiang Meng, ${ }^{\text {b }}$ Guokui Liu (D) *c and \\ Yangyang Dang (iD *a
}

\begin{abstract}
Lead-free copper-based halide hybrid materials have emerged as a class of potential candidates for next-generation optoelectronic devices. In this work, we demonstrated that $\mathrm{Gua}_{4} \mathrm{Cu}_{4} \mathrm{Br}_{8}$ and $\mathrm{Gua}_{3} \mathrm{Cu}_{2} \mathrm{I}_{5}$ (Gua $=\mathrm{CH}_{6} \mathrm{~N}_{3}{ }^{+}$) single crystals have been successfully grown by slow evaporation methods in an ambient atmosphere. Interestingly, non-centrosymmetric $\mathrm{Gua}_{6} \mathrm{Cu}_{4} \mathrm{l}_{10}$ single crystals were formed on the basis of $\mathrm{Gua}_{3} \mathrm{Cu}_{2} \mathrm{I}_{5}$ induced by chiral $(R)$ - and (S)-methylbenzylamine (MBA) cations. In particular, $\mathrm{Gua}_{3} \mathrm{Cu}_{2} \mathrm{I}_{5}$ exhibited a large Stokes shift of about $200 \mathrm{~nm}$ with a long PL lifetime of about $3835 \mathrm{~ns}$ and an absolute PLQY of about $72.04 \%$ at room temperature. More importantly, ultraviolet (UV)-pumped light-emitting diodes based on $\mathrm{Gua}_{3} \mathrm{Cu}_{2} \mathrm{l}_{5}$ single crystals exhibited strong photoluminescence characteristics at an emission peaking position of about $575 \mathrm{~nm}$ with high luminance. The above characteristics should provide guidance for further applications of lead-free hybrid single-crystalline optoelectronic devices.
\end{abstract}

\section{Introduction}

Hybrid lead-free copper halide materials have attracted attention in optoelectronic devices such as solar cells, ${ }^{1-3}$ field-effect transistors (FETs), ${ }^{4,5}$ light emitting diodes (LEDs), ${ }^{6,7}$ resistive switching memory devices, ${ }^{8,9}$ circularly polarized luminescence (CPL) based devices, ${ }^{10}$ photodetectors, ${ }^{11,12}$ etc. Most of the perovskite studies mainly focused on Pb-based halide hybrids, which suffered from the important issues of stability ${ }^{13,14}$ and intrinsic toxicity. ${ }^{15,16}$ Therefore, the above studies urged materials scientists to investigate new lead-free halide hybrids with excellent optoelectronic properties and stability. To search for environmentally friendly lead-free halide hybrids with outstanding optoelectronic properties, there is an effective strategy to replace $\mathrm{Pb}$ with low-toxic tin $(\mathrm{Sn}),{ }^{17-19}$ manganese $(\mathrm{Mn}),{ }^{20,21}$ and copper $(\mathrm{Cu})^{22-25}$ in lead halide perovskites, which can not

\footnotetext{
${ }^{a}$ School of Physics and Physical Engineering, Shandong Provincial Key Laboratory of Laser Polarization and Information Technology, Qufu Normal University, Qufu, 273165, P. R. China. E-mail: dyy@qfnu.edu.cn

${ }^{b}$ Materials Interfaces Center, Shenzhen Institutes of Advanced Technology, Chinese Academy of Sciences, Shenzhen 518055, P. R. China. E-mail: lq.meng@siat.ac.cn ${ }^{c}$ School of Chemistry and Chemical Engineering, Linyi University, Linyi 276000, P. R. China. E-mail: liuguokuihappy@163.com

$\dagger$ Electronic supplementary information (ESI) available: XPS spectra, crystal data, spatial distributions calculation, TGA/DSC diagrams, PL spectra, PL lifetime and PLQY. CCDC 2113134-2113136. For ESI and crystallographic data in CIF or other electronic format see DOI: $10.1039 / \mathrm{d} 1 \mathrm{ma} 01055 \mathrm{~g}$
}

only eliminate the toxicity of $\mathrm{Pb}$ but also obtain excellent physical characteristics such as high mobility, strong photoluminescence and good stability. Sn-based halide perovskite materials exhibited excellent semiconducting properties, and were widely used in FETs. ${ }^{26}$ Mn-based halide perovskites possessed good photoluminescence characteristics, which were applied to light-emitting and scintillating devices. ${ }^{27,28}$ Moreover, nontoxic transition metal $\mathrm{Cu}$ is an ideal candidate for $\mathrm{Pb}$ to form $\mathrm{Cu}$-based halide hybrid compounds. Previous studies on Cu-based halide perovskite materials focused on divalent $\mathrm{Cu}(\mathrm{II})$ compounds, most of which are powders and thin films. ${ }^{29,30}$ The structural and magnetic properties of $\left(4,4^{\prime}\right.$ bipyridinium $) \mathrm{Cu}_{2} \mathrm{Cl}_{6-x} \mathrm{Br}_{x}$ are investigated. ${ }^{31}$ Reversible and irreversible thermochromism behaviors of copper(II)-based halide perovskites were demonstrated. ${ }^{32}$ The thermochromic behaviors of two perovskites (2-chloroethylammonium) ${ }_{2} \mathrm{CuCl}_{4}$ and (2-bromoethylammonium) ${ }_{2} \mathrm{CuCl}_{4}$ were discussed. ${ }^{32}$ The above studies mainly focused on divalent $\mathrm{Cu}$ (II)-based halide perovskites exhibiting poor photoluminescence characteristics, which hinders their application in the optoelectronic field. Recently, $\mathrm{Cu}(\mathrm{I})$-based halide compounds with excellent photoluminescence properties urged us to investigate these issues of $\mathrm{Cu}(\mathrm{I})$-based halide analogues. The all-inorganic $\mathrm{Cu}(\mathrm{I})$-based halide perovskite $\mathrm{Cs}_{3} \mathrm{Cu}_{2} \mathrm{I}_{5}$ with a bright blue emission and a high photoluminescence quantum yield (PLQY) of $\sim 91.2 \%$ was first reported by Jun et al. ${ }^{33}$ Then, high-performance and stable yellow LEDs based on solution-processed $\mathrm{CsCu}_{2} \mathrm{I}_{3}$ thin films 
were fabricated. ${ }^{34}$ Stable UV-pumped white light-emitting diodes based on anthracene-coated $\mathrm{CsCu}_{2} \mathrm{I}_{3}$ were demonstrated by Liu et al. ${ }^{6}$ All-inorganic blue emitters $\mathrm{K}_{2} \mathrm{CuX}_{3}(\mathrm{X}=\mathrm{Cl}, \mathrm{Br})$ and $\mathrm{Cs}_{3} \mathrm{Cu}_{2} \mathrm{Br}_{5-x} \mathrm{I}_{x}(0 \leq x \leq 5)$ with near-unity PLQY were investigated by the Saparov research group. ${ }^{35,36}$ Nontoxic and ultrastable LEDs based on $1 \mathrm{D}-\mathrm{Cu}_{4} \mathrm{I}_{6}(\text { bttmp })_{2}$ thin films were prepared by Zhu et al., which exhibited a high PLQY and long-term air stability. ${ }^{7}$ Recently, highly efficient cool-white photoluminescence characteristics of $\mathrm{Gua}_{3} \mathrm{Cu}_{2} \mathrm{I}_{5}$ (Gua = guanidine) single crystals in DMF in an inert atmosphere were investigated by Peng et al. ${ }^{37}$ Opaque $\mathrm{Gua}_{3} \mathrm{Cu}_{2} \mathrm{I}_{5}$ single crystals exhibit highly efficient cool-white emission peaking at $481 \mathrm{~nm}$. At higher temperatures, $\mathrm{Gua}_{3} \mathrm{Cu}_{2} \mathrm{I}_{5}$ single crystals exhibited yellow emission, while at room temperature, they exhibited blue emission. Therefore, it is necessary to introduce different organic molecules into the lattice of $\mathrm{Gua}_{3} \mathrm{Cu}_{2} \mathrm{I}_{5}$ and form new photoluminescent materials by solution synthesis and growth methods in an ambient atmosphere.

In this work, bulk colourless $\mathrm{Gua}_{4} \mathrm{Cu}_{4} \mathrm{Br}_{8}$ and $\mathrm{Gua}_{3} \mathrm{Cu}_{2} \mathrm{I}_{5}$ (Gua $=\mathrm{CH}_{6} \mathrm{~N}_{3}{ }^{+}$) single crystals were successfully grown by a slow evaporation method in an ambient atmosphere. Interestingly, non-centrosymmetric $\mathrm{Gua}_{6} \mathrm{Cu}_{4} \mathrm{I}_{10}$ single crystals were formed on the basis of $\mathrm{Gua}_{3} \mathrm{Cu}_{2} \mathrm{I}_{5}$ induced by chiral $(R)$ - and $(S)$-methylbenzylamine (MBA) cations. The band gap, theoretical calculations, X-ray photoelectron spectra (XPS), thermal stability and optical properties of $\mathrm{Gua}_{4} \mathrm{Cu}_{4} \mathrm{Br}_{8}$ and $\mathrm{Gua}_{3} \mathrm{Cu}_{2} \mathrm{I}_{5}$ were studied, which exhibited a large Stokes shift with a long PL decay lifetime. Both $\mathrm{Gua}_{4} \mathrm{Cu}_{4} \mathrm{Br}_{8}$ and $\mathrm{Gua}_{3} \mathrm{Cu}_{2} \mathrm{I}_{5}$ are direct band gap semiconductor materials. As we all know, $\mathrm{Gua}_{3} \mathrm{Cu}_{2} \mathrm{I}_{5}$ crystals exhibited good luminescence properties. ${ }^{37}$ From the viewpoint of crystal structures, $\mathrm{Gua}_{4} \mathrm{Cu}_{4} \mathrm{Br}_{8}$ single crystals were introduced to analyse the crystal structure and PL differences induced by the $\mathrm{Br}$ and I atoms. Similarly, we tried to compare $\mathrm{Gua}_{3} \mathrm{Cu}_{2} \mathrm{I}_{5}$ and $\mathrm{Gua}_{6} \mathrm{Cu}_{4} \mathrm{I}_{10}$ induced by chiral MBA cations. The PL decay lifetime and PLQY exhibited obvious difference due to the different crystal structures. Based on these results, it is concluded that $\mathrm{Gua}_{3} \mathrm{Cu}_{2} \mathrm{I}_{5}$ exhibited the strongest luminescence properties among the three single crystals. Therefore, ultraviolet (UV)-pumped yellow light-emitting diodes based on $\mathrm{Gua}_{3} \mathrm{Cu}_{2} \mathrm{I}_{5}$ single crystals were fabricated, which exhibited strong photoluminescence characteristics at an emission peaking position of about $575 \mathrm{~nm}$ with a luminance of about $3600 \mathrm{~cd} \mathrm{~m}^{-2}$. The above behaviours should pave the way for further optoelectronic applications of these single-crystalline materials.

\section{Results and discussion}

A previous report ${ }^{37}$ has shown that opaque single crystals of blue emissive $\mathrm{Gua}_{3} \mathrm{Cu}_{2} \mathrm{I}_{5}$ were formed in organic solvents in an inert atmosphere. Due to the ease of oxidation of copper(I), it is challenging to obtain copper(I) halide perovskite single crystals in an ambient atmosphere. According to eqn (1)-(3) of redox potentials, $\mathrm{H}_{3} \mathrm{PO}_{2}$ was used as a reducing reagent to prevent the oxidation of $\mathrm{I}^{-}$and $\mathrm{Cu}^{+}$. If the amount of $\mathrm{H}_{3} \mathrm{PO}_{2}$ is too little, the oxidation of $\mathrm{Cu}^{+}$and $\mathrm{I}^{-}$can easily occur. In contrast, an excessive amount of $\mathrm{H}_{3} \mathrm{PO}_{2}$ is too viscous to be beneficial for crystal growth. Therefore, all the growth conditions were maintained in an ambient atmosphere. Bulk colourless $\mathrm{Gua}_{4} \mathrm{Cu}_{4} \mathrm{Br}_{8}$ and $\mathrm{Gua}_{3} \mathrm{Cu}_{2} \mathrm{I}_{5}$ single crystals have been grown at room temperature by slow evaporation methods for one week (Fig. 1). When exposed to UV-254 $\mathrm{nm}$ and $365 \mathrm{~nm}$ irradiation conditions, bulk colourless $\mathrm{Gua}_{4} \mathrm{Cu}_{4} \mathrm{Br}_{8}$ and $\mathrm{Gua}_{3} \mathrm{Cu}_{2} \mathrm{I}_{5}$ single crystals

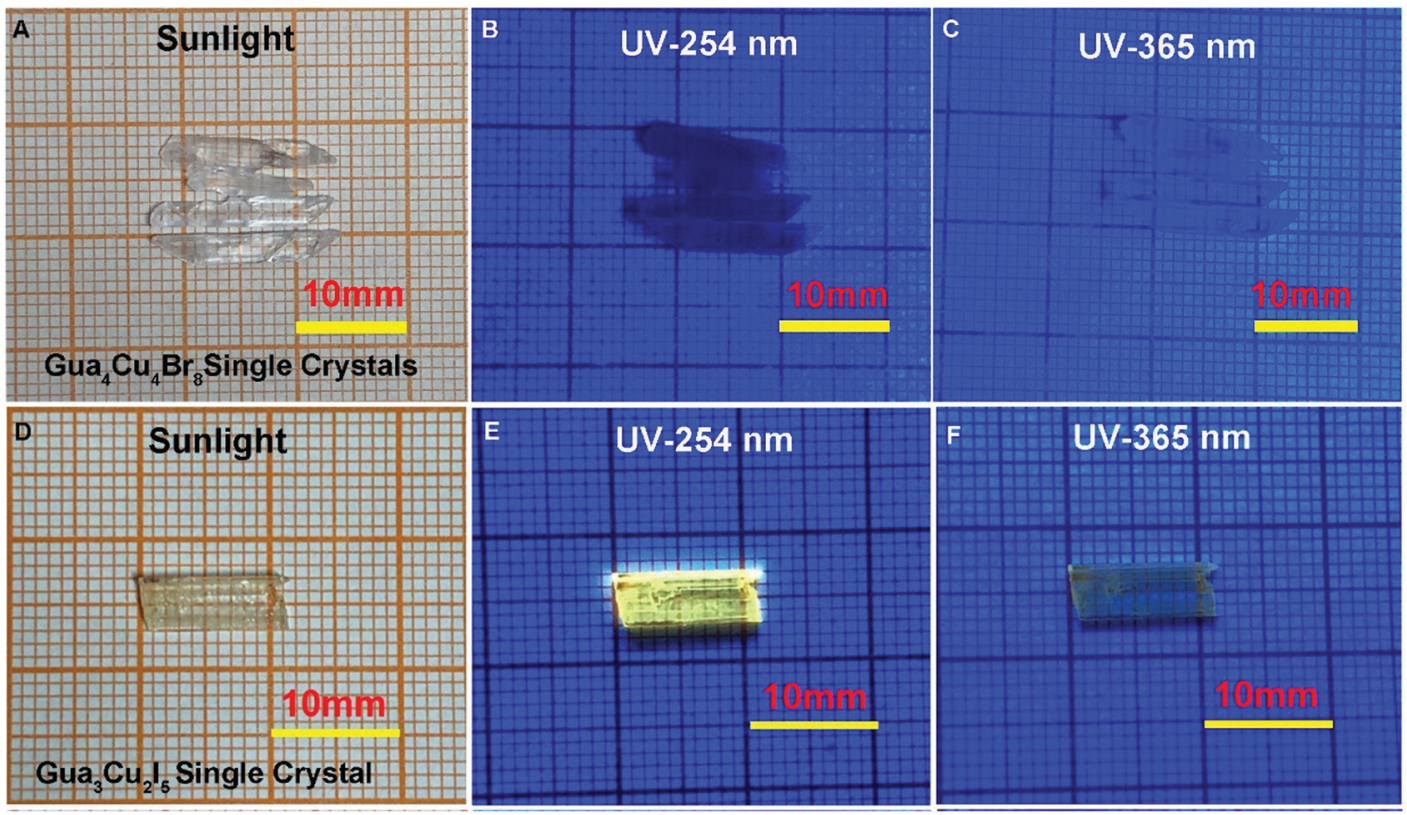

Fig. 1 Photographs of $\mathrm{Gua}_{4} \mathrm{Cu}_{4} \mathrm{Br}_{8}$ single crystals under sunlight (A), UV-254 nm (B) and UV-365 nm (C) conditions. Photographs of Gua $\mathrm{Cu}_{2} \mathrm{I}_{5}$ single crystals under sunlight (D), UV-254 nm (E) and UV-365 nm (F) conditions. 
exhibited different photoluminescence characteristics as shown in Fig. $1(\mathrm{~B}, \mathrm{C})$ and $(\mathrm{E}, \mathrm{F})$. In particular, $\mathrm{Gua}_{3} \mathrm{Cu}_{2} \mathrm{I}_{5}$ single crystals exhibited strong yellow emission under irradiation of UV-254 nm wavelength as shown in Fig. 1E. In the Gua-Cu-Br formation, $\mathrm{Gua}_{2} \mathrm{CO}_{3}$ reacted with $\mathrm{CuBr}$ in a molar ratio of $1: 2$ in $\mathrm{HBr}$ and $\mathrm{H}_{3} \mathrm{PO}_{2}$ mixed solution at $60{ }^{\circ} \mathrm{C}$ in an ambient atmosphere. In the formation processes of $\mathrm{Gua}-\mathrm{Cu}-\mathrm{I}$ systems, $\mathrm{Gua}_{2} \mathrm{CO}_{3}$ reacted with $\mathrm{CuI}$ in a molar ratio of $3: 4$ in $\mathrm{HI}$ and $\mathrm{H}_{3} \mathrm{PO}_{2}$ mixed solution at $70{ }^{\circ} \mathrm{C}$ in an ambient atmosphere. Previously, Tang's research group reported chiral tetranuclear copper(I) iodide clusters based on the $(R)$ - and $(S)$-MBA. ${ }^{38} \mathrm{Cu}^{+}$is easily connected with $(R)$ - and $(S)$-MBA so as to form a tetrahedral coordination environment. But in $\mathrm{HI}$ and $\mathrm{H}_{3} \mathrm{PO}_{2}$ mixed solution, the $\mathrm{Cu}-(R) /(S)$-MBA clusters were completely replaced by $\mathrm{I}^{-}$. Interestingly, $\mathrm{Gua}_{3} \mathrm{Cu}_{2} \mathrm{I}_{5}$ reacted with chiral $R$-or $S$-MBA in a molar ratio of $2: 1$ in $\mathrm{HI}$ and $\mathrm{H}_{3} \mathrm{PO}_{2}$ mixed solution to promote the formation of non-centrosymmetric $\mathrm{Gua}_{6} \mathrm{Cu}_{4} \mathrm{I}_{10}$ single crystals as shown in Fig. S1 (ESI $\dagger$ ).

$$
\begin{aligned}
& \mathrm{H}_{3} \mathrm{PO}_{3}(\mathrm{aq})+2 \mathrm{H}^{+}+2 \mathrm{e}^{-}=\mathrm{H}_{3} \mathrm{PO}_{2}(\mathrm{aq})+\mathrm{H}_{2} \mathrm{O} E=-0.499 \mathrm{eV} \\
& \mathrm{Cu}^{2+}+\mathrm{e}^{-}=\mathrm{Cu}^{+} E=+0.159 \mathrm{eV} \\
& \mathrm{I}_{2}+2 \mathrm{e}^{-}=2 \mathrm{I}^{-} E=+0.54 \mathrm{eV}
\end{aligned}
$$

Differently, a previous report revealed that $\mathrm{Gua}_{3} \mathrm{Cu}_{2} \mathrm{I}_{5}$ exhibited an orthorhombic system with the space group Fdd2 (no. 43). ${ }^{37} \mathrm{Gua}_{4} \mathrm{Cu}_{4} \mathrm{Br}_{8}$ and $\mathrm{Gua}_{3} \mathrm{Cu}_{2} \mathrm{I}_{5}$ single crystals crystallized in monoclinic systems of $P 2_{1} / n$ (no. 14) and $C 2 / c$ (no. 15) space groups by single-crystal X-ray diffraction measurements at room temperature for the first time. All the crystallographic data are listed in Table S1 (ESI $\dagger$ ). In the crystal structure of $\mathrm{Gua}_{4} \mathrm{Cu}_{4} \mathrm{Br}_{8}$, the adjacent four $\mathrm{Cu}$ atoms were coordinated with ten bromine atoms (Fig. 2A), forming a special $\left\{\mathrm{Cu}_{4} \mathrm{Br}_{10}\right\}$ facesharing tetrahedral unit. In addition, the $\left\{\mathrm{Cu}_{4} \mathrm{Br}_{10}\right\}$ polyhedra are connected from the same layer and surrounded by Gua cations. Moreover, although the atomic radius of $\mathrm{I}$ is larger than that of $\mathrm{Br}$, the adjacent four $\mathrm{Cu}$ atoms are coordinated with seven iodine atoms forming a polyhedral unit as shown in Fig. 2C. This structure is connected from the same layer and surrounded by Gua cations to form the layered structures, which is different from the isolated $\left\{\mathrm{Cu}_{2} \mathrm{I}_{5}\right\}$ face-sharing tetrahedral dimer. ${ }^{37}$ The powder X-ray diffraction (PXRD) patterns of all the materials are in good agreement with the simulated XRD diffraction patterns of these single crystals, as shown in Fig. 2(B, D) and Fig. S1C (ESI $\dagger$ ). Next, X-ray photoelectron spectroscopy (XPS) measurements were performed to investigate the valence state of elements in $\mathrm{Gua}_{4} \mathrm{Cu}_{4} \mathrm{Br}_{8}$ and $\mathrm{Gua}_{3} \mathrm{Cu}_{2} \mathrm{I}_{5}$ single crystals. All the XPS results are demarcated using $\mathrm{C} 1 \mathrm{~s}$
A
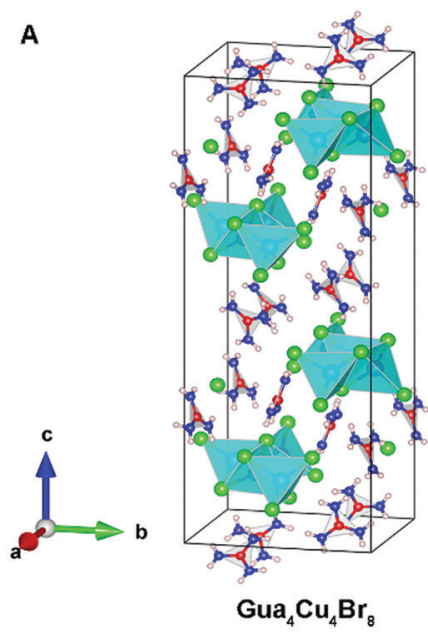

C

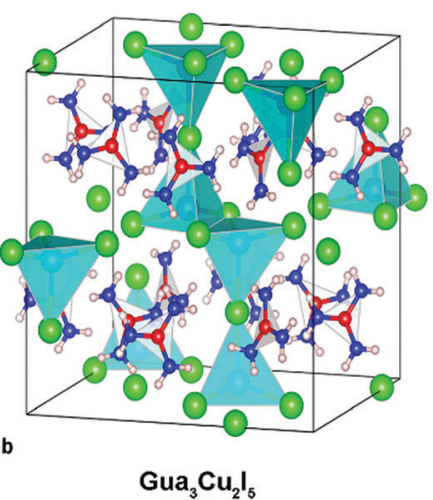

B

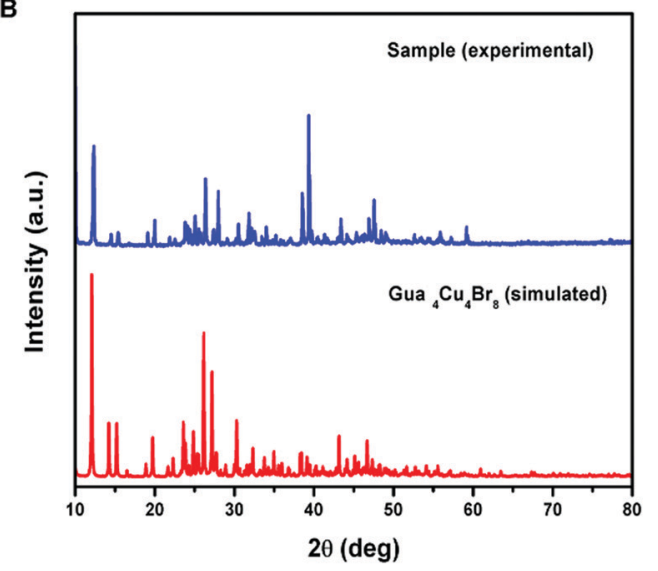

D

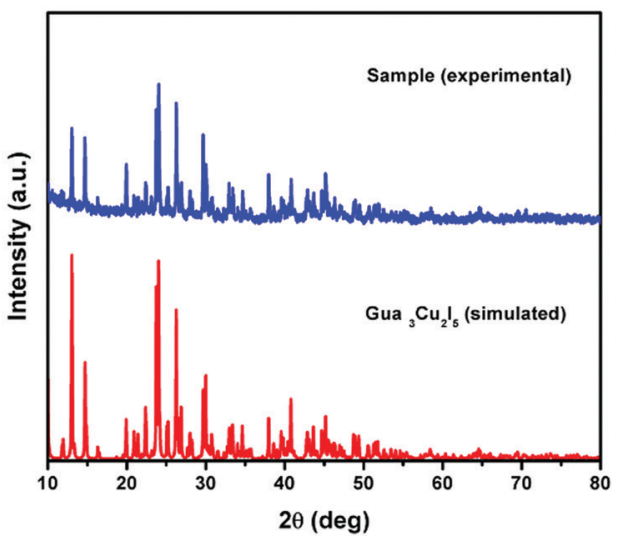

Fig. 2 (A) Crystal structure of $\mathrm{Gua}_{4} \mathrm{Cu}_{4} \mathrm{Br}_{8}$. (B) Powder and single-crystal X-ray diffraction (PXRD) patterns of $\mathrm{Gua}_{4} \mathrm{Cu}_{4} \mathrm{Br}_{8}$. (C) $\mathrm{Crystal}_{3}$ structure of $\mathrm{Gua}_{3} \mathrm{Cu}_{2} \mathrm{I}_{5}$. (D) PXRD patterns of $\mathrm{Gu}_{3} \mathrm{Cu}_{2} \mathrm{I}_{5}$. 


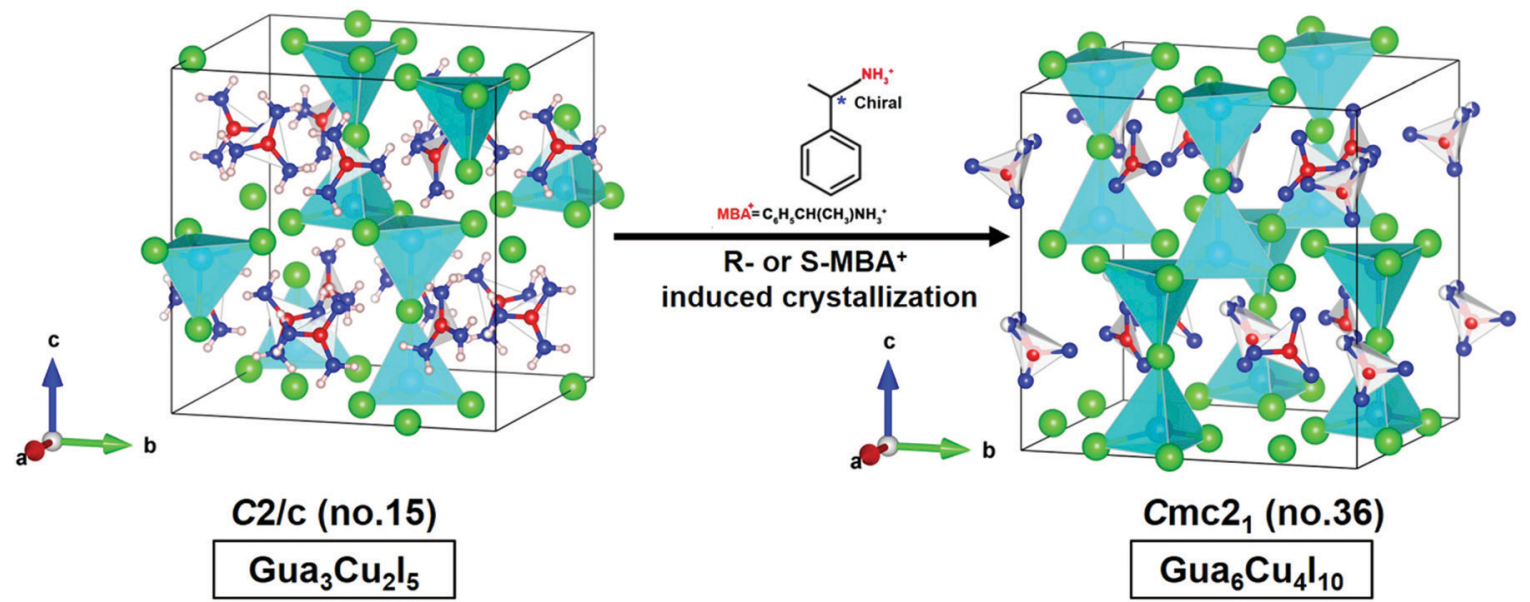

Fig. 3 Crystal structural transformations from $\mathrm{Gua}_{3} \mathrm{Cu}_{2} \mathrm{I}_{5}$ to $\mathrm{Gua}_{6} \mathrm{Cu}_{4} \mathrm{I}_{10}$ induced by chiral MBA cations.

$(284.8 \mathrm{eV})$ as the reference. These results confirm the existence of $\mathrm{Br}, \mathrm{I}$ and $\mathrm{Cu}$ elements. The high-resolution core-level XPS spectra of $\mathrm{C} 1 \mathrm{~s}, \mathrm{~N} 1 \mathrm{~s}, \mathrm{Cu} 2 \mathrm{p}, \mathrm{Br} 3 \mathrm{~d}$ and I $3 \mathrm{~d}$ are extracted, as shown in Fig. S2 (ESI $\dagger$ ). Cu 2p XPS spectra are the prominent characteristics for verifying the $\mathrm{Cu}$ oxidation state, which means that the $\mathrm{Cu}(\mathrm{I})$ state plays a dominant role in $\mathrm{Gua}_{4} \mathrm{Cu}_{4} \mathrm{Br}_{8}$ and $\mathrm{Gua}_{3} \mathrm{Cu}_{2} \mathrm{I}_{5}$ single crystals. The HRXPS spectrum peak at a binding energy of about $933 \mathrm{eV}$ can hardly be observed, ${ }^{39}$ which further eliminates the existence of the $\mathrm{Cu}(\mathrm{II})$ state. The binding energies are located at about 932 and $952 \mathrm{eV}$, corresponding to $\mathrm{Cu} 2 \mathrm{p}_{3 / 2}$ and $\mathrm{Cu} 2 \mathrm{p}_{1 / 2}$, respectively. Moreover, no shake-up satellite appears between the $\mathrm{Cu} 2 \mathrm{p}_{3 / 2}$ and $\mathrm{Cu} 2 \mathrm{p}_{1 / 2}$ peaks, indicating that only $\mathrm{Cu}(\mathrm{I})$ ions exist in the lattice, ${ }^{40-42}$ which confirms that all the samples are both pure phase copper(I) based halide hybrids. From the above description, the presence of $\mathrm{I}^{-}, \mathrm{Br}^{-}, \mathrm{CH}_{6} \mathrm{~N}_{3}{ }^{+}$and $\mathrm{Cu}^{+}$verifies the chemical composition and valence state of $\mathrm{Gua}_{4} \mathrm{Cu}_{4} \mathrm{Br}_{8}$ and $\mathrm{Gua}_{3} \mathrm{Cu}_{2} \mathrm{I}_{5}$ single crystals.

The structural transformation usually involves bond rearrangements and composition changes of atoms in a crystal caused by the changes in the coordination number of metals, the addition of different ligands, temperature changes or solvent exchanges. ${ }^{43-45}$ Interestingly, single crystal-to-single crystal phase transformations from $\mathrm{Gua}_{3} \mathrm{Cu}_{2} \mathrm{I}_{5}$ to $\mathrm{Gua}_{6} \mathrm{Cu}_{4} \mathrm{I}_{10}$ occurred induced by the effect on the chiral $R$-or $S$-MBA. $\mathrm{Gua}_{6} \mathrm{Cu}_{4} \mathrm{I}_{10}$ single crystals under sunlight and UV-254 nm wavelength conditions are shown in Fig. S1A and B (ESI $\dagger$ ). $\mathrm{Gua}_{6} \mathrm{Cu}_{4} \mathrm{I}_{10}$ single crystals exhibited an orthorhombic system with $C m c 2_{1}$ (no. 36) with the lattice parameters of $a=12.072(3) \AA$, $b=13.215(3) \AA$, and $c=13.581(3) \AA . \mathrm{Gua}_{3} \mathrm{Cu}_{2} \mathrm{I}_{5}$ exhibited the lattice parameters of $a=12.0317(9) \AA, b=13.2491(10) \AA$, and $c=13.5695(10) \AA ; \beta=90.985(7)^{\circ}$ in Table S1 (ESI $\dagger$ ). The lattice parameters of $\mathrm{Gua}_{6} \mathrm{Cu}_{4} \mathrm{I}_{10}$ are larger than those of $\mathrm{Gua}_{3} \mathrm{Cu}_{2} \mathrm{I}_{5}$. In the crystal structure of $\mathrm{Gua}_{6} \mathrm{Cu}_{4} \mathrm{I}_{10}$, the strong distortions of the $\left\{\mathrm{Cu}_{3} \mathrm{I}_{6}\right\}$ polyhedral unit can be caused by the Gua parts, which results in an acentric structure as shown in Fig. 3. As stated above, $\mathrm{Gua}_{6} \mathrm{Cu}_{4} \mathrm{I}_{10}$ single crystals were easily formed and crystallized when $\mathrm{Gua}_{3} \mathrm{Cu}_{2} \mathrm{I}_{5}$ single crystals were exposed to $R$ - and $S$-MBA cations.
Subsequently, the optical band gap of $\mathrm{Gua}_{4} \mathrm{Cu}_{4} \mathrm{Br}_{8}$ and $\mathrm{Gua}_{3} \mathrm{Cu}_{2} \mathrm{I}_{5}$ was investigated. The optical band gap is determined using the Kubelka-Munk function. ${ }^{46} \mathrm{~A}$ previous study ${ }^{37}$ has demonstrated the optical band gap of blue emissive $\mathrm{Gua}_{3} \mathrm{Cu}_{2} \mathrm{I}_{5}$ powders in an air atmosphere. A distinct feature peak at $366 \mathrm{~nm}$ can be observed, which corresponds to the calculated band gap of $2.98 \mathrm{eV}$. In our results, the optical band gaps of $\mathrm{Gua}_{4} \mathrm{Cu}_{4} \mathrm{Br}_{8}$ and $\mathrm{Gua}_{3} \mathrm{Cu}_{2} \mathrm{I}_{5}$ in Fig. $4 \mathrm{~A}$ and B were $3.6 \mathrm{eV}$
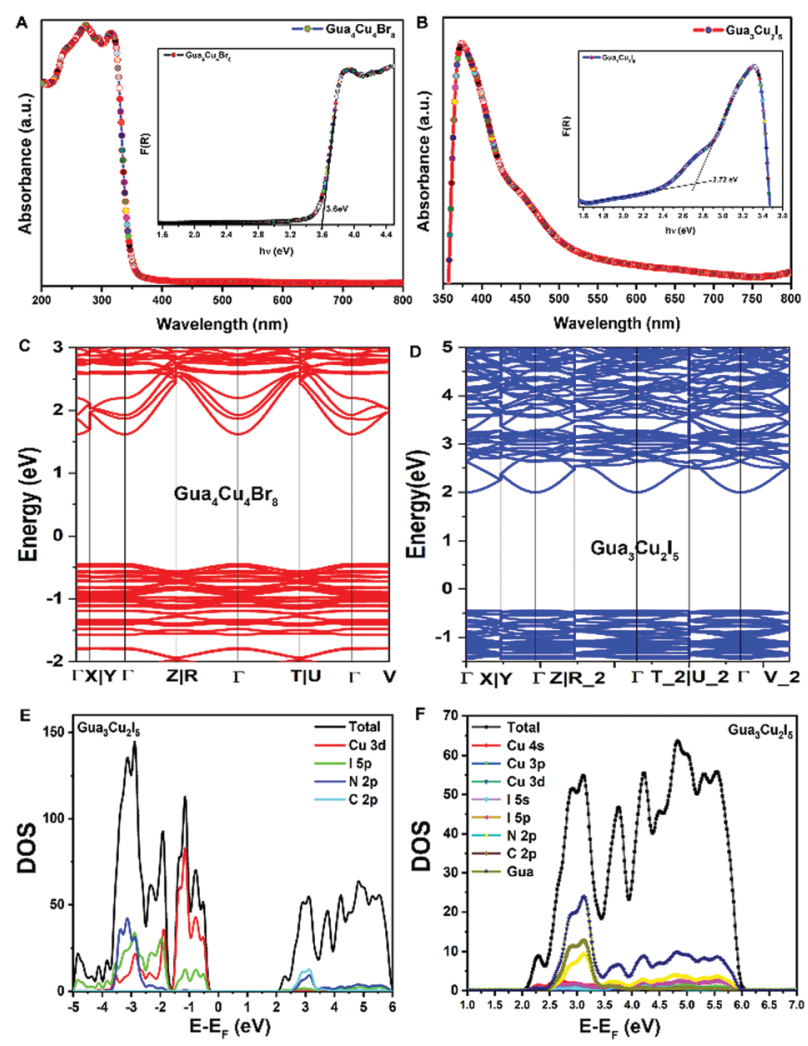

Fig. 4 Optical band gap of $\mathrm{Gua}_{4} \mathrm{Cu}_{4} \mathrm{Br}_{8}$ (A) and $\mathrm{Gua}_{3} \mathrm{Cu}_{2} \mathrm{I}_{5}$ (B). DFT band structures of $\mathrm{Gua}_{4} \mathrm{Cu}_{4} \mathrm{Br}_{8}(\mathrm{C})$ and $\mathrm{Gua}_{3} \mathrm{Cu}_{2} \mathrm{I}_{5}(\mathrm{D})$. Projected density of states (PDOS) plots of the $\mathrm{Gua}_{3} \mathrm{Cu}_{2} \mathrm{I}_{5}$ via DFT calculations (E). Detailed projected density of states (PDOS) plots of the $\mathrm{Gua}_{3} \mathrm{Cu}_{2} \mathrm{I}_{5}$ via DFT calculations (F). 
and $2.72 \mathrm{eV}$, respectively. The electronic properties of $\mathrm{Gua}_{4}$ $\mathrm{Cu}_{4} \mathrm{Br}_{8}$ and $\mathrm{Gua}_{3} \mathrm{Cu}_{2} \mathrm{I}_{5}$ were determined by the density functional theory (DFT) calculation method, as shown in Fig. 4C and $\mathrm{D}$, both of which exhibited the direct band gap semiconductors, according to the calculation method based on a previous report. ${ }^{47}$ PBE functional calculations ${ }^{48}$ generally underestimate the band gap. Differently, blue emissive $\mathrm{Cua}_{3}$ $\mathrm{Cu}_{2} \mathrm{I}_{5}$ exhibited a direct band gap of $2.75 \mathrm{eV}$ at the $\mathrm{G}$ point. ${ }^{37}$ However, from Fig. $4 \mathrm{D}$, yellow emissive $\mathrm{Cua}_{3} \mathrm{Cu}_{2} \mathrm{I}_{5}$ showed a band gap of $2.44 \mathrm{eV}$ at the $\Gamma$ point. The detailed projected density of states (PDOS) in Fig. $4 \mathrm{E}$ and $\mathrm{F}$ indicates that the valence band maximum (VBM) of yellow emissive $\mathrm{Cua}_{3} \mathrm{Cu}_{2} \mathrm{I}_{5}$ is composed of inorganic parts, $\mathrm{Cu} 3 \mathrm{~d}$ and I $5 \mathrm{p}$ atomic orbitals. However, for the conduction band minimum (CBM), the contribution of specific atomic orbitals cannot be found obviously. To study the composition of the CBM, we calculated more states of PDOS as shown in Fig. 4F. Although the $4 \mathrm{~S}$ orbital of $\mathrm{Cu}$ accounts for the highest proportion, its height is very low in comparison with the height of total DOS. Other orbitals of I 5s, I 5p, and partly Gua molecules make second contribution with a similar proportion. To further explain the PDOS diagrams of the VBM and CBM, the spatial distribution of charge density is plotted. It can be seen from Fig. S3A (ESI $\dagger$ ) that the VBM is mainly composed of Cu3d and I5p atomic orbitals. In Fig. S3B (ESI $\dagger$ ), the distribution of the CBM is more interesting. The charge density distribution is wide. Both $\mathrm{C}$ and $\mathrm{N}$ atoms on Gua molecules show little charge density distribution. The main distribution is concentrated on the $\mathrm{Cu}$ atoms sharing two I atoms. The distance between the two $\mathrm{Cu}$ atoms is relatively close, about $2.55 \AA$. The $4 \mathrm{~s}$ orbitals of $\mathrm{Cu}$ atoms overlap partially, which is similar to the distribution of $\pi$ orbitals. Moreover, it should be noted that the 5s and 5p orbitals of I atoms are also partially involved in the CBM. This also explains the distribution of the CBM. The CBM is no longer composed of pure $\mathrm{Cu} 4 \mathrm{~s}$ orbitals. The main compositions for the CBM are the overlapping $4 \mathrm{~s}$ orbitals of $\mathrm{Cu}$ atoms that share two I atoms.

Previously, the emissions of $\mathrm{Gua}_{3} \mathrm{Cu}_{2} \mathrm{I}_{5}$ single crystals exhibited a reversible phase transition from blue to yellow color in a heating-cooling cycle. ${ }^{37}$ The thermogravimetry analysis (TGA) measurements of $\mathrm{Gua}_{4} \mathrm{Cu}_{4} \mathrm{Br}_{8}$ and $\mathrm{Gua}_{3} \mathrm{Cu}_{2} \mathrm{I}_{5}$ were performed from room temperature to $600{ }^{\circ} \mathrm{C}$ as shown in Fig. S4 (ESI $\dagger$ ). It can be seen that $\mathrm{Gua}_{4} \mathrm{Cu}_{4} \mathrm{Br}_{8}$ and $\mathrm{Gua}_{3} \mathrm{Cu}_{2} \mathrm{I}_{5}$ are stable up to about $300{ }^{\circ} \mathrm{C}$. In particular, the emission colour changes of $\mathrm{Gua}_{3} \mathrm{Cu}_{2} \mathrm{I}_{5}$ single crystals when exposed to heating and cooling processes under the irradiation of UV-254 $\mathrm{nm}$ wavelength cannot be observed in Fig. S5 (ESI $\dagger$ ). They both showed relatively good thermal stability. Furthermore, the PL spectra and the PL decay lifetime measurements of $\mathrm{Gua}_{4} \mathrm{Cu}_{4} \mathrm{Br}_{8}$ and $\mathrm{Gua}_{3} \mathrm{Cu}_{2} \mathrm{I}_{5}$ powders and single crystals were performed as shown in Fig. $5 \mathrm{Gua}_{4} \mathrm{Cu}_{4} \mathrm{Br}_{8}$ and $\mathrm{Gua}_{3} \mathrm{Cu}_{2} \mathrm{I}_{5}$ powders and single crystals exhibited broad PL peaks, which was similar to the previous reports on perovskite materials. ${ }^{49}$ From Fig. 5A and B, the excitonic absorption bands of $\mathrm{Gua}_{4} \mathrm{Cu}_{4} \mathrm{Br}_{8}$ and $\mathrm{Gua}_{3} \mathrm{Cu}_{2} \mathrm{I}_{5}$ powders and single crystals were positioned at $330 \mathrm{~nm}$ and $325 \mathrm{~nm}$, respectively. The PL excitation (PLE) and PL spectra of $\mathrm{Gua}_{4} \mathrm{Cu}_{4} \mathrm{Br}_{8}$ and $\mathrm{Gua}_{3} \mathrm{Cu}_{2} \mathrm{I}_{5}$ powders and single crystals also
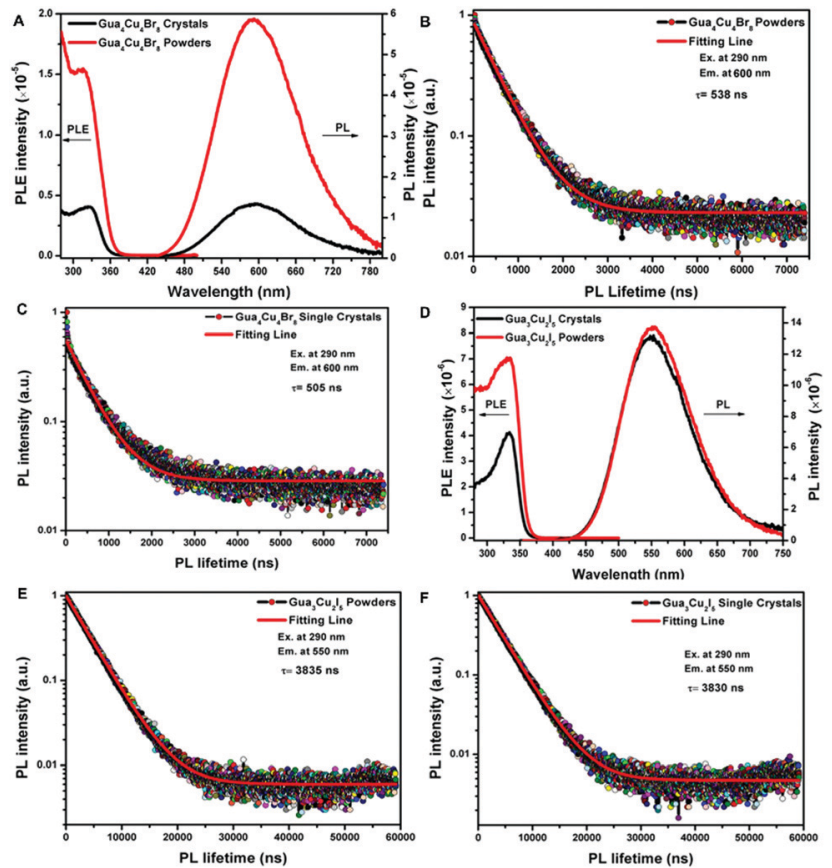

Fig. 5 PLE and PL spectra of $\mathrm{Gua}_{4} \mathrm{Cu}_{4} \mathrm{Br}_{8}$ (A). PL decay lifetime of Gua $_{4} \mathrm{Cu}_{4} \mathrm{Br}_{8}$ powders (B) and single crystals (C). PLE and PL spectra of $\mathrm{Gua}_{3} \mathrm{Cu}_{2} \mathrm{I}_{5}$ (D). PL decay lifetime of $\mathrm{Gua}_{3} \mathrm{Cu}_{2} \mathrm{I}_{5}$ powders (E) and single crystals (F).

exhibited only one PL peak at about $600 \mathrm{~nm}$ and $575 \mathrm{~nm}$, respectively. However, the excitonic absorption band of $\mathrm{Gua}_{6-}$ $\mathrm{Cu}_{4} \mathrm{I}_{10}$ single crystals exhibited was positioned at $340 \mathrm{~nm}$. The PL spectra of $\mathrm{Gua}_{6} \mathrm{Cu}_{4} \mathrm{I}_{10}$ single crystals also exhibited only one PL peak at about $560 \mathrm{~nm}$ in Fig. S1D (ESI $\dagger$ ). Such broad luminescence and a large stoke shift were attributed to selftrapped excitons. ${ }^{50-52}$ The time-resolved photoluminescence (TRPL) spectra of $\mathrm{Gua}_{4} \mathrm{Cu}_{4} \mathrm{Br}_{8}$ and $\mathrm{Gua}_{3} \mathrm{Cu}_{2} \mathrm{I}_{5}$ powders and single crystals were well fitted by the first-order exponential decay function, as shown in Fig. 5B, C, E and F. The PL decay lifetime $(\tau)$ of $\mathrm{Gua}_{4} \mathrm{Cu}_{4} \mathrm{Br}_{8}$ powders and single crystals was 538 ns and 505 ns with an absolute photoluminescence quantum yield (PLQY) of less than 1\% when exposed to excitation at $290 \mathrm{~nm}$ and emission at $600 \mathrm{~nm}$. However, $\mathrm{Gua}_{3} \mathrm{Cu}_{2} \mathrm{I}_{5}$ powders and single crystals exhibit yellow luminescence with PL decay lifetimes of $3835 \mathrm{~ns}(3.835 \mu \mathrm{s})$ and $3830 \mathrm{~ns}(3.830 \mu \mathrm{s})$ under the conditions of excitation at $290 \mathrm{~nm}$ and emission at $550 \mathrm{~nm}$. And the absolute PLQY of $\mathrm{Gua}_{3} \mathrm{Cu}_{2} \mathrm{I}_{5}$ is about $72.04 \%$ as shown in Fig. S6 (ESI $\dagger$ ). However, the TRPL spectrum of $\mathrm{Gua}_{6} \mathrm{Cu}_{4} \mathrm{I}_{10}$ powders agreed well with the biexponential decay function. The average PL decay lifetime $(\tau)$ of $\mathrm{Gua}_{6} \mathrm{Cu}_{4} \mathrm{I}_{10}$ powders was $6.29 \mu \mathrm{s}$ with an absolute PLQY of $12.07 \%$ when exposed to excitation at $330 \mathrm{~nm}$ and emission at $550 \mathrm{~nm}$ in Fig. S7 and S8 (ESI $\dagger$ ).

As descripted above, a high PL intensity and yellow emission of $\mathrm{Gua}_{3} \mathrm{Cu}_{2} \mathrm{I}_{5}$ perovskite materials urged us to employ the obtained perovskite single crystals for LED applications. There has been a previous report on the utilization of $\mathrm{Gua}_{3} \mathrm{Cu}_{2} \mathrm{I}_{5}$ perovskite powders for UV-pumped LEDs exhibiting bright cool-white emissions. ${ }^{37}$ Differently, we introduced $\mathrm{Gua}_{3} \mathrm{Cu}_{2} \mathrm{I}_{5}$ 

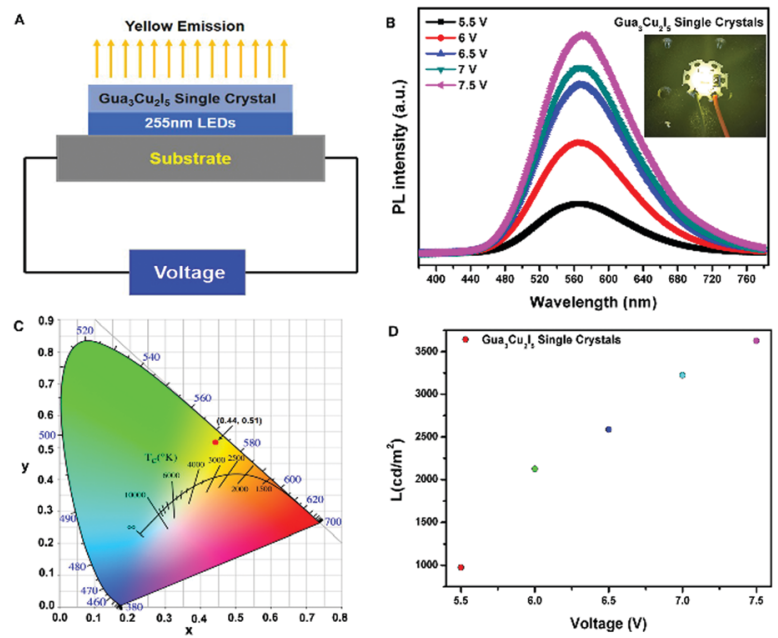

Fig. 6 (A) Schematic illustration of fabricated UV-pumped LEDs based on $\mathrm{Gua}_{3} \mathrm{Cu}_{2} \mathrm{I}_{5}$ single crystals. (B) PL intensity of $\mathrm{Gua}_{3} \mathrm{Cu}_{2} \mathrm{I}_{5}$ single-crystalline UV-pumped LED devices under the excitation of UV-255 nm LED chips at different working voltages. Inset: The photograph of $\mathrm{Gua}_{3} \mathrm{Cu}_{2} \mathrm{I}_{5}$ singlecrystalline UV-pumped LEDs at a work voltage of $7.5 \mathrm{~V}$. (C) CIE chromaticity diagram of $\left.\mathrm{Gua}_{3} \mathrm{Cu}_{2}\right|_{5}$ at room temperature. (D) Luminance-voltage diagram of $\mathrm{Gua}_{3} \mathrm{Cu}_{2} \mathrm{I}_{5}$ single crystal-based UV-pumped LEDs.

single crystals into UV-pumped LEDs. The commercial UV-LED (255 nm) chip was used to optically pump different phosphor mixtures. $\mathrm{Gua}_{3} \mathrm{Cu}_{2} \mathrm{I}_{5}$ single crystals were assembled with a $255 \mathrm{~nm}$ UV-LED chip to form LEDs, as illustrated in Fig. 6(A, B) and Movie S1 (ESI $\dagger$ ). The broad emission spectra of UVpumped LEDs based on $\mathrm{Gua}_{3} \mathrm{Cu}_{2} \mathrm{I}_{5}$ single crystals are shown in Fig. $6 \mathrm{~B}$. The PL intensity of the LEDs based on $\mathrm{Gua}_{3} \mathrm{Cu}_{2} \mathrm{I}_{5}$ single crystals increases with an increase in the working voltage from 5.5 to $7.5 \mathrm{~V}$, indicating the high photoluminescence characteristics. The PL spectra presented an emission peak of UVpumped LEDs at around $575 \mathrm{~nm}$, which correspond to the emissions of $\mathrm{Gua}_{3} \mathrm{Cu}_{2} \mathrm{I}_{5}$ single crystals. From Fig. 6C, the measurement results at room temperature demonstrated that the CIE color coordinate is $(0.44,0.51)$, which agreed well with the yellow emission region. With the increase of working voltage from 5.5 to $7.5 \mathrm{~V}$, the luminance of UV-pumped LEDs also increased and reached up to about $3600 \mathrm{~cd} \mathrm{~m}^{2}$ as shown in Fig. 6D. These results show that the yellow light emitted from the LEDs based on $\mathrm{Gua}_{3} \mathrm{Cu}_{2} \mathrm{I}_{5}$ single crystals exhibited high luminance, which can further promote the applications of

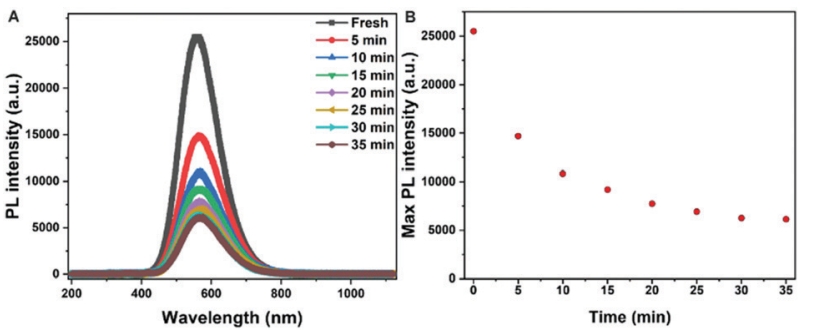

Fig. 7 (A) PL intensity and (B) the maximum intensity of $\mathrm{Gua}_{3} \mathrm{Cu}_{2} \mathrm{I}_{5}$ singlecrystalline UV-pumped LED devices under the excitation of UV-255 nm LED chips after different running times. high-brightness LEDs and other optoelectronic devices. Moreover, the operational stability measurements of $\mathrm{Gua}_{3} \mathrm{Cu}_{2} \mathrm{I}_{5}$ single crystal-based LEDs were performed under UV light (255 nm) excitation for 35 minutes in air, as shown in Fig. 7. And the PL intensity was recorded every 5 minutes. The PL intensity gradually decreased with the increase of time. The possible reason is that the oxidation and decompositions of $\mathrm{Gua}_{3} \mathrm{Cu}_{2} \mathrm{I}_{5}$ single crystals happen when exposed to light and air. ${ }^{53}$ If encapsulations of these devices are performed, $\mathrm{Gua}_{3-}$ $\mathrm{Cu}_{2} \mathrm{I}_{5}$ single crystal-based LEDs will exhibit relatively good photoluminescence.

\section{Conclusions}

In summary, we have demonstrated that $\mathrm{Gua}_{4} \mathrm{Cu}_{4} \mathrm{Br}_{8}$ and $\mathrm{Gua}_{3} \mathrm{Cu}_{2} \mathrm{I}_{5}$ single crystals with photoluminescence characteristics were grown by slow evaporation methods in air. Acentric $\mathrm{Gua}_{6} \mathrm{Cu}_{4} \mathrm{I}_{10}$ single crystals originated from $\mathrm{Gua}_{3} \mathrm{Cu}_{2} \mathrm{I}_{5}$ single crystals induced by $(R)$ - and $(S)$-MBA cations. The obtained copper(I) halide perovskites exhibited strong PL emissions and large Stoke shifts (about $200 \mathrm{~nm}$ ) between their absorption and emission spectra. Color coordinates of $(0.44,0.51)$ and a high luminance of up to $3600 \mathrm{~cd} \mathrm{~m}^{-2}$ were obtained based on $\mathrm{Gua}_{3} \mathrm{Cu}_{2} \mathrm{I}_{5}$ single-crystalline UV pumped LEDs, which can provide broad prospects for potential applications in solid-state lighting and displays.

\section{Experimental}

\section{Materials}

$\mathrm{CuI}(\mathrm{AR}, \mathrm{J} \& \mathrm{~K}), \mathrm{CuBr}(\mathrm{AR}, \mathrm{J} \& \mathrm{~K}), \mathrm{Gua}_{2} \mathrm{CO}_{3}$ (AR, J\&K), $\mathrm{H}_{3} \mathrm{PO}_{2}(\mathrm{AR}$, $\mathrm{J} \& \mathrm{~K}), \mathrm{HI}(57 \%, \mathrm{~J} \& \mathrm{~K}), \mathrm{HBr}(48 \%, \mathrm{~J} \& \mathrm{~K}), R$-MBA, and $S$-MBA were purchased from Sino-pharm and utilized without further purification.

\section{Synthesis and crystal growth}

$\mathrm{Gua}_{4} \mathrm{Cu}_{4} \mathrm{Br}_{8}$ was synthesized with a reaction of $\mathrm{Gua}_{2} \mathrm{CO}_{3}$ and $\mathrm{CuBr}$ with a molar ratio of $1: 2$ in mixed acid $\left(\mathrm{HBr} / \mathrm{H}_{3} \mathrm{PO}_{2}=3: 1\right)$ solution. $\mathrm{Gua}_{2} \mathrm{CO}_{3}(0.3650 \mathrm{~g}, 2 \mathrm{mmol})$ and $\mathrm{CuBr}(0.5710 \mathrm{~g}$, $4 \mathrm{mmol})$ were dissolved in $\mathrm{HBr}(6 \mathrm{~mL})$ and $\mathrm{H}_{3} \mathrm{PO}_{2}(2 \mathrm{~mL})$ solution at $60{ }^{\circ} \mathrm{C}$ temperature to form a colourless solution. And then the solution was cooled to room temperature. Bulk $\mathrm{Gua}_{4} \mathrm{Cu}_{4} \mathrm{Br}_{8}$ single crystals were formed by a slow evaporation method in an ambient atmosphere as shown in Fig. 1A.

$\mathrm{Gua}_{3} \mathrm{Cu}_{2} \mathrm{I}_{5}$ was synthesized with a reaction of $\mathrm{Gua}_{2} \mathrm{CO}_{3}$ and CuI with a molar ratio of $3: 4$ in mixed acid $\left(\mathrm{HI} / \mathrm{H}_{3} \mathrm{PO}_{2}=2: 1\right)$ solution. $\mathrm{Gua}_{2} \mathrm{CO}_{3}(1.0910 \mathrm{~g}, 6 \mathrm{mmol})$ and $\mathrm{CuI}(1.5250 \mathrm{~g}$, $8 \mathrm{mmol})$ were dissolved in $\mathrm{HI}(8 \mathrm{~mL})$ and $\mathrm{H}_{3} \mathrm{PO}_{2}(4 \mathrm{~mL})$ solution at $70{ }^{\circ} \mathrm{C}$ temperature to form a light-yellow solution. And then the solution was cooled to room temperature. Bulk $\mathrm{Gua}_{3} \mathrm{Cu}_{2} \mathrm{I}_{5}$ single crystals were formed by a slow evaporation method in an ambient atmosphere as shown in Fig. 1D.

$\mathrm{Gua}_{6} \mathrm{Cu}_{4} \mathrm{I}_{10}$ was synthesized with a reaction of $\mathrm{Gua}_{3} \mathrm{Cu}_{2} \mathrm{I}_{5}$ and $R / S$-MBA with a molar ratio of $2: 1$ in mixed acid $\left(\mathrm{HI} / \mathrm{H}_{3} \mathrm{PO}_{2}=2: 1\right)$ solution. $\mathrm{Gua}_{3} \mathrm{Cu}_{2} \mathrm{I}_{5}(3.7560 \mathrm{~g}, 4 \mathrm{mmol})$ and 
$R / S$-MBA $(0.2435 \mathrm{~g}, 2 \mathrm{mmol})$ were dissolved in $\mathrm{HI}(12 \mathrm{~mL})$ and $\mathrm{H}_{3} \mathrm{PO}_{2}(6 \mathrm{~mL})$ solution at $70{ }^{\circ} \mathrm{C}$ temperature to form a lightyellow solution. And then the solution was cooled to room temperature. Bulk Gua $\mathrm{Cu}_{4} \mathrm{I}_{10}$ single crystals were formed by a slow evaporation method in an ambient atmosphere as shown in Fig. S3 (ESI $\dagger$ ).

Slow evaporation was carried out under the following conditions: oil bath $\left(35^{\circ} \mathrm{C}\right)$, humidity $(20 \%)$ and atmospheric pressure.

\section{Powder and single crystal X-ray diffraction measurements}

X-Ray powder diffraction patterns were determined on a PANalytical XPert Pro MPD equipment with $\mathrm{Cu}-\mathrm{K}_{\mathrm{a}}$ radiation in the $2 \theta$ range of $100^{\circ}-90^{\circ}$ using reasonable step size and step time settings. Single-crystal X-ray diffraction data were collected on a Bruker D8 advance diffractometer equipped with a CCD detector (graphite-monochromated Mo-Ka radiation, $\lambda=0.71073 \AA$ ) at 293(2) K. APEX3 software was used for data integration and cell refinements. The crystal was kept at 293(2) K during data collection. Using Olex $2{ }^{54}$ the structure was solved with the Olex2.solve ${ }^{55}$ structure solution program using Charge Flipping and refined with the $\mathrm{XL}^{56}$ refinement package using Least Squares minimization.

\section{X-Ray photoelectron spectroscopy (XPS) measurements}

Polycrystalline samples were extracted using a sample transporter that protects against air exposure. The sample transporter is connected to an ultra-high vacuum chamber and then transferred to the XPS systems for characterization. Pass energy values are $160 \mathrm{eV}$ for XPS wide scan, and $10 \mathrm{eV}$ for high resolution scan. All the data analysis about XPS was performed using the XPS Peaks Fit software. All the elements were fitted with the $80 \%$ Gaussian and $20 \%$ Lorentzian peak shapes after applying background subtractions with Shirley function. ${ }^{57}$

UV-Vis and steady-state, time-resolved photoluminescence (PL) spectrum measurements

The optical absorption spectra were recorded using a UV-Vis absorption spectrophotometer (PerkinElmer, Lambda 1050). Steady-state, time-resolved photoluminescence (PL) spectra were recorded with a photoluminescence system (HORIBA, FluoroLog-3). The powder and single crystalline samples were placed in a holder applied to the photoluminescence system. The absolute PLQY of all the samples was measured, which was coated on the $\mathrm{BaSO}_{4}$ standard sample.

\section{Simulation details}

Structural optimization was performed via the Vienna ab initio simulation package (VASP) ${ }^{58,59}$ with the conjugate gradient method. The Perdew, Burke, and Ernzerhof exchange-correlation functional within GGA was used. ${ }^{60}$ The convergence of energy between two electronic steps in the self-consistent process was set to $10-5 \mathrm{eV}$. Ionic relaxation was stopped when the maximum force was smaller than $0.01 \mathrm{eV}^{-1}$. All atoms in the models and the cell shape and volume were fully relaxed. A Monkhorst-Pack grid of $3 \times 2 \times 2$ is used for the reciprocal space sampling. ${ }^{61}$ An energy cut-off of $450 \mathrm{eV}$ was adopted for plane-wave expansion of electronic wave functions.

\section{Thermogravimetric analysis measurements}

Thermogravimetric analysis (TGA) was carried out using a TGA/ DSC1/1600HT analyzer (METTLER TOLEDO Instruments). All the powder samples were placed in an $\mathrm{Al}_{2} \mathrm{O}_{3}$ crucible, and heated at a rate of $10{ }^{\circ} \mathrm{C} \mathrm{min}{ }^{-1}$ from room temperature to $600{ }^{\circ} \mathrm{C}$ under flowing $\mathrm{N}_{2}$ gas, respectively.

\section{UV-Pumped LEDs fabrication and measurements}

The PL, CIE chromaticity and luminance characteristics of UV-pumped LEDs were investigated using a PR-788 spectrophotometer (Photo Research) and a Keithley-2400 instrument. For fabricating UV-pumped LEDs, regular $\mathrm{Gua}_{3} \mathrm{Cu}_{2} \mathrm{I}_{5}$ single crystals were placed on commercial UV LED chips with $255 \mathrm{~nm}$ emission wavelength as the pumping source for LEDs as shown in Fig. 6(A, B) and Movie S1 (ESI $\dagger$ ). The fabricated LED devices were placed in the measurement equipment.

\section{Author contributions}

Y. D. designed the experiment; Y. D. and Z. S. performed the crystal growth and the crystallographic experiments. L. M. and B. Y. performed and analysed the property characterization including steady-state PL, TRPL, UV-vis diffuse reflectance spectroscopy and UV-pumped LED fabrications. G. L. contributed to theoretical calculations. Y. D. and Z. S. wrote the paper. L. M. and G. L. revised the paper and provided valuable suggestions. All authors revised and approved the final version of the manuscript for submission.

\section{Conflicts of interest}

There are no conflicts to declare.

\section{Acknowledgements}

This work is supported by the National Natural Science Foundation of China (Grant No. 51802215). All the authors thank Dr Jing Wei, Beijing Institute of Technology, and Dr Chunlong Li, Qilu University of Technology for their help in XPS and TGA measurements.

\section{Notes and references}

1 Z. Shi, J. Guo, Y. Chen, Q. Li, Y. Pan, H. Zhang, Y. Xia and W. Huang, Adv. Mater., 2017, 29, 1605005.

2 D. Cortecchia, H. Dewi, A. Yin, J. Bruno, A. Chen, S. Baikie, T. Boix, P. P. Grätzel, M. Mhaisalkar, S. Soci and C. N. Mathews, Inorg. Chem., 2016, 55, 1044.

3 X. Li, B. Li, J. Chang, B. Ding, S. Zheng, Y. Wu, J. Yang, G. Yang, X. Zhong and J. Wang, ACS Appl. Energy Mater., 2018, 1, 2709. 
4 C.-H. Choi, J. Y. Gorecki, Z. Fang, M. Allen, S. Li, L.-Y. Lin, C.-C. Cheng and C.-H. Chang, J. Mater. Chem. C, 2016, 4, 10309.

5 A. Liu, H. Zhu, W. T. Park, S. J. Kang, Y. Xu, M.-G. Kim and Y.-Y. Noh, Adv. Mater., 2018, 30, 1802379.

6 W. Liu, K. W. Ng, H. Lin, Z. Dai, J. Xu, S. Su, Z. Tang and S. Wang, J. Phys. Chem. C, 2021, 125, 13076.

7 K. Zhu, Z. Cheng, S. Rangan, M. Cotlet, J. Du, L. Kasaei, S. J. Teat, W. Liu, Y. Chen, L. C. Feldman, D. M. O’Carroll and J. Li, ACS Energy Lett., 2021, 6, 2565.

8 S.-Y. Kim, J.-M. Yang, E.-S. Choi and N.-G. Park, Adv. Funct. Mater., 2020, 30, 2002653.

9 F. Zeng, Y. Guo, W. Hu, Y. Tan, X. Zhang, J. Feng and X. Tang, ACS Appl. Mater. Interfaces, 2020, 12, 23094.

10 Y. Dang, X. Liu, B. Cao and X. Tao, Matter, 2021, 4, 794.

11 Y. Li, Z. Shi, L. Wang, Y. Chen, W. Liang, D. Wu, X. Li, Y. Zhang, C. Shan and X. Fan, Mater. Horiz., 2020, 7, 1613.

12 J. Ma, X. Xia, S. Yan, Y. Li, W. Liang, J. Yan, X. Chen, D. Wu, X. Li and Z. Shi, ACS Appl. Mater. Interfaces, 2021, 13, 15409.

13 W. Xiang, S. F. Liu and W. Tress, Energy Environ. Sci., 2021, 14, 2090.

14 B. Ehrler and E. M. Hutter, Matter, 2020, 2, 794.

15 A. Babayigit, A. Ethirajan, M. Muller and B. Conings, Nat. Mater., 2016, 15, 247.

16 A. L. Wani, A. Ara and J. A. Usmani, Interdiscip. Toxicol., 2015, 8, 55.

17 Y. Dang, Y. Zhou, X. Liu, D. Ju, S. Xia, H. Xia and X. Tao, Angew. Chem., Int. Ed., 2016, 55, 3447.

18 L. He, H. Gu, X. Liu, P. Li, Y. Dang, C. Liang, L. K. Ono, Y. Qi and X. Tao, Matter, 2020, 2, 167.

19 Y. Dang, C. Zhong, G. Zhang, D. Ju, L. Wang, S. Xia, H. Xia and X. Tao, Chem. Mater., 2016, 28, 6968.

20 J. Zhao, T. Zhang, X.-Y. Dong, M.-E. Sun, C. Zhang, X. Li, Y. Zhao and S.-Q. Zang, J. Am. Chem. Soc., 2019, 141, 15755.

21 G. Hu, B. Xu, A. Wang, Y. Guo, J. Wu, F. Muhammad, W. Meng, C. Wang, S. Sui, Y. Liu, Y. Li, Y. Zhang, Y. Zhou and Z. Deng, Adv. Funct. Mater., 2021, 31, 2011191.

22 L. Xie, B. Chen, F. Zhang, Z. Zhao, X. Wang, L. Shi, Y. Liu, L. Huang, R. Liu, B. Zou and Y. Wang, Photonics Res., 2020, 8, 768.

23 Z. Xiao, K.-Z. Du, W. Meng, D. B. Mitzi and Y. Yan, Angew. Chem., Int. Ed., 2017, 56, 12107.

24 Z. Xiao, Z. Song and Y. Yan, Adv. Mater., 2019, 31, 1803792.

25 J. Lin, H. Chen, J. Kang, L. N. Quan, Z. Lin, Q. Kong, M. Lai, S. Yu, L. Wang, L. Wang, M. F. Toney and P. Yang, Matter, 2019, 1, 180.

26 C. Chen, X. Zhang, G. Wu, H. Li and H.-Z. Chen, Adv. Opt. Mater., 2017, 5, 1600539.

27 L. Hou, Y. Zhu, J. Zhu, Y. Gong and C. Li, J. Mater. Chem. C, 2020, 8, 8502.

28 J.-H. Wei, J.-F. Liao, X.-D. Wang, L. Zhou, Y. Jiang and D.-B. Kuang, Matter, 2020, 3, 892.

29 B. A. Connor, R. W. Smaha, J. Li, A. Gold-Parker, A. J. Heyer, M. F. Toney, Y. S. Lee and H. I. Karunadasa, Chem. Sci., 2021, 12, 8689.

30 M. Wang, W. Wang, B. Ma, W. Shen, L. Liu, K. Cao, S. Chen and W. Huang, Nano-Micro Lett., 2021, 13, 62.
31 R. D. Willett, R. E. Butcher, C. P. Landee and B. Twamley, Polyhedron, 2006, 25, 2093.

32 C. Pareja-Rivera and D. Solis-Ibarra, Adv. Opt. Mater., 2021, 9, 2100633.

33 T. Jun, K. Sim, S. Iimura, M. Sasase, H. Kamioka, J. Kim and H. Hosono, Adv. Mater., 2018, 30, 1804547.

34 X. Mo, T. Li, F. Huang, Z. Li, Y. Zhou, T. Lin, Y. Ouyang, X. Tao and C. Pan, Nano Energy, 2021, 81, 105570.

35 T. D. Creason, T. M. McWhorter, Z. Bell, M. Du and B. Saparov, Chem. Mater., 2020, 32, 6197-6205.

36 R. Roccanova, A. Yangui, H. Nhalil, H. Shi, M.-H. Du and B. Saparov, ACS Appl. Electron. Mater., 2019, 1, 269.

37 H. Peng, X. Wang, Y. Tian, B. Zou, F. Yang, T. Huang, C. Peng and S. Yao, ACS Appl. Mater. Interfaces, 2021, 13, 13443.

38 L. Yao, G. Niu, J. Li, L. Gao, X. Luo, B. Xia and Y. Liu, J. Phys. Chem. Lett., 2020, 11, 1255.

39 M. C. Biesinger, Surf. Interface Anal., 2017, 49, 1325.

40 P. Cheng, L. Sun, L. Feng, S. Yang, Y. Yang, D. Zheng, Y. Zhao, Y. Sang, R. Zhang, D. Wei, W. Deng and K. Han, Angew. Chem., Int. Ed., 2019, 58, 16087.

41 L. Xie, B. Chen, F. Zhang, Z. Zhao, X. Wang, L. Shi, Y. Liu, L. Huang, R. Liu, B. Zou and Y. Wang, Photonics Res., 2020, 8, 768.

42 T. Li, X. Mo, C. Peng, Q. Lu, C. Qi, X. Tao, Y. Ouyang and Y. Zhou, Chem. Commun., 2019, 55, 4554.

43 C. G. Bischak, M. Lai, Z. Fan, D. Lu, P. David, D. Dong, H. Chen, A. S. Etman, T. Lei, J. Sun, M. Grünwald, D. T. Limmer, P. Yang and N. S. Ginsberg, Matter, 2020, 3, 534 .

44 Z. Li, Y. Sun, H. Yao, J. Zhao, Q. Wang, L. Ding and Z. Jin, J. Energy Chem., 2021, 52, 102.

45 S. Liu, H. Liu, G. Zhou, X. Li and S. Wang, Chem. Eng. J., 2022, 427, 131430.

46 W. M. Wendlandt and H. G. Hecht, Reflectance spectroscopy, Wiley Interscience, New York, 1966, p. 62.

47 P. Fu, S. Hu, J. Tang and Z. Xiao, Front. Optoelectron., 2021, 14, 252.

48 J. P. Perdew, K. Burke and M. Ernzerhof, Phys. Rev. Lett., 1996, 77, 3865.

49 G. Zhou, B. Su, J. Huang, Q. Zhang and Z. Xia, Mater. Sci. Eng., $R$, 2020, 141, 100548.

50 L. Lian, M. Zheng, P. Zhang, Z. Zheng, K. Du, W. Lei, J. Gao, G. Niu, D. Zhang, T. Zhai, S. Jin, J. Tang, X. Zhang and J. Zhang, Chem. Mater., 2020, 32, 3462.

51 H. Chen, J. M. Pina, F. Yuan, A. Johnston, D. Ma, B. Chen, Z. Li, A. Dumont, X. Li, Y. Liu, S. Hoogland, Z. Zajacz, Z. Lu and E. H. Sargent, J. Phys. Chem. Lett., 2020, 11, 4326.

52 B. Zhang, X. Wu, S. Zhou, G. Liang and Q. Hu, Front. Optoelectron., 2021, 14, 459.

53 H. Shankar, A. Jha and P. Kar, Mater. Adv., 2022, 3, 658.

54 O. V. Dolomanov, L. J. Bourhis, R. J. Gildea, J. A. K. Howard and H. Puschmann, J. Appl. Crystallogr., 2009, 42, 339.

55 L. J. Bourhis, O. V. Dolomanov, R. J. Gildea, J. A. K. Howard and H. Puschmann, Acta Crystallogr., Sect. A: Found. Adv., 2015, 71, 59. 
56 G. M. Sheldrick, Acta Crystallogr., Sect. A: Found. Crystallogr., 2008, 64, 112.

57 W. Song, K. Leung, Q. Shao, K. J. Gaskell and J. E. ReuttRobey, J. Phys. Chem. C, 2016, 120, 22979.

58 G. Kresse and J. Furthmüller, Comput. Mater. Sci., 1996, 6, 15.
59 G. Kresse and J. Furthmüller, Phys. Rev. B: Condens. Matter Mater. Phys., 1996, 54, 11169-11186.

60 J. P. Perdew, K. Burke and M. Ernzerhof, Phys. Rev. Lett., 1996, 77, 3865.

61 H. J. Monkhorst and J. D. Pack, Phys. Rev. B: Condens. Matter Mater. Phys., 1976, 13, 5188. 